\title{
Papillary thyroid cancer with simultaneous iodine-avidity and iodine-resistance in a pregnant patient
}

\author{
Helen Gharwan ${ }^{1}$, Henry G. Fein ${ }^{2}$ \\ 1. Johns Hopkins University/Sinai Hospital of Baltimore, Department of Internal Medicine, Baltimore, Maryland, USA. \\ 2. Division of Endocrinology, Sinai Hospital of Baltimore, Baltimore, Maryland, USA
}

Correspondence: Helen Gharwan. Address: Johns Hopkins University/Sinai Hospital of Baltimore, Department of Internal Medicine, Baltimore 21215-5271, Maryland, USA. E-mail: hgh7@hotmail.com

Received: March 21, 2013

Accepted: April 6, 2013

Online Published: April 12, 2013

DOI : $10.5430 /$ jst.v3n3p34

URL: http://dx.doi.org/10.5430/jst.v3n3p34

\section{Abstract}

Objective: To report the case of a 21-year-old pregnant woman, who was diagnosed with papillary thyroid cancer (PTC) and lytic bone lesions ten years after chemotherapy (CHOP) and mini-mantle field radiation for Hodgkin's lymphoma; To discuss the association of second malignant neoplasms in childhood Hodgkin's lymphoma survivors, and to hypothesize on the possible etiology and significance of the lack of radioiodine avidity in our patient's bony lesions.

Methods: We describe the patient's symptoms as well as the laboratory, radiographic and histopathology results leading to the diagnosis of PTC.

Results: After having been diagnosed with PTC, our patient elected to undergo abortion prior to total thyroidectomy. Iodine-123 scan after surgery showed uptake in the thyroid bed, but none in the bony lesions raising concern for a second primary malignancy, possibly originating from the organs that had been in the field of her previous radiation. However, biopsy confirmed PTC as the cause for the bone destructions. Palliative external beam radiation of the bony lesions was performed. Sorafenib treatment was offered to her, but declined. She died a few months later of respiratory failure secondary to pronounced muscle weakness.

Conclusion: The concomitant presence of iodine-avidity and -resistance reflects de-differentiation of the tumor cells, and it is associated with poor prognosis. We hypothesize that the combination of pregnancy and previous radiation may have caused the cancer's marked aggressiveness.

\section{Key words}

Thyroid, Papillary thyroid cancer, Hodgkin’s lymphoma, Radioiodine, Pregnancy

\section{I ntroduction}

While the incidence rates of papillary thyroid cancer (PTC) in women of all ethnic/ancestral groups rise during their reproductive years, peak in their early fifties, and decline in later decades, they are lowest among blacks than among other ethnic groups ${ }^{[1]}$. About $10 \%$ of thyroid cancers occurring during the reproductive years of women are diagnosed during pregnancy or in the first year after child birth ${ }^{[2]}$. In fact, thyroid cancer is the most frequently diagnosed cancer type in 
pregnant women six to nine months before delivery ${ }^{[3]}$. The Endocrine Society recommends to not terminate pregnancy, but to perform thyroidectomy after delivery in patients without evidence of advanced disease or rapid progression, and surgery in the second trimester for others ${ }^{[4]}$. After delivery, iodine-131 ablation may be required depending on tumor stage and histology.

Although higher disease recurrence and persistence rates have been reported in cases of pregnancy-related TC, according to the medical literature ${ }^{[5]}$, the overall survival of pregnant patients with differentiated TC appears to be similar to nonpregnant women.

Here we report the unusually dramatic disease course of a young black woman with a history of previous therapeutic radiation for Hodgkin's lymphoma in childhood, who was diagnosed with stage IV PTC at initial presentation and who was found to be pregnant at the time of cancer diagnosis.

\section{Case}

A 21-year-old black woman with a negative family history for malignancies presented with gradually worsening pain in her upper thoracic spine that had been ongoing since one year and recently interfered with her sleep. She also complained of sternal pain that was exacerbated by laughing and coughing, and paresthesias of her left upper extremity. Hodgkin's lymphoma had been diagnosed at the age of eleven years. She was treated with chemotherapy (CHOP) and consolidative external beam radiation (2100 cGy) to a mini-mantle field, and she had been in remission for nine years. Two years ago she gave birth to a girl.

Figure 1. CT scan of the cervical and thoracic spine: The areas of lytic bone destructions are highlighted
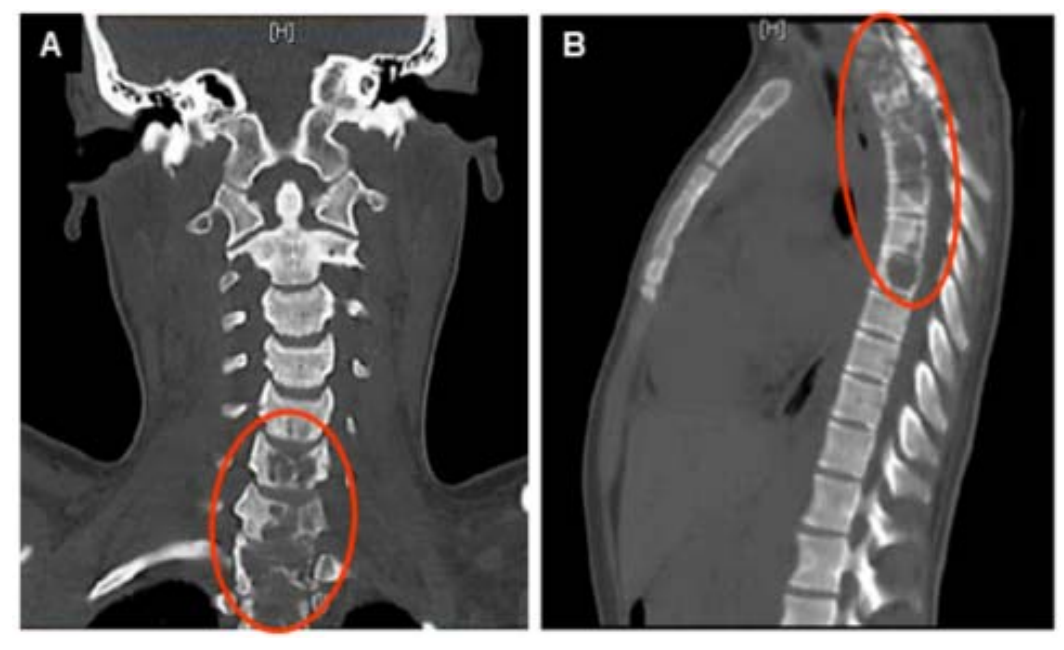

On physical examination thyromegaly and tenderness of the cervical and thoracic spine, of bilateral paraspinal muscles and the sternum were noted. Computed tomography scans of the spine and chest revealed lytic lesions in all vertebrae from C6 to T8 (Figures 1A and B) and in the manubrium sterni. Magnetic resonance imaging of the cervical and thoracic spine demonstrated compression fractures of the T1 and T3 vertebral bodies, probable cord compression at the T3 level, epidural extension of the mass lesion at the C7 to T1 level, retropulsion of bone fragments causing spinal stenosis (Figure 2A), and an enlarged nodular thyroid gland (Figure 2B). Laboratory evaluation revealed normal chemistries and mild anemia. She was euthyroid (FT4 $0.78 \mathrm{ng} / \mathrm{dL}$, TSH $1.61 \mathrm{mcIU} / \mathrm{mL}$ ), but her thyroglobulin level was dramatically elevated at $5339 \mathrm{ng} / \mathrm{mL}$ (normal: $1.6 \mathrm{ng} / \mathrm{mL}-59.9 \mathrm{ng} / \mathrm{mL}$ ). Anti-thyroglobulin antibody was less than 20 (normal: 0-40). Thyroid ultrasonography showed multiple adjoining thyroid nodules replacing the right lobe. Fine needle aspiration of the largest nodule revealed PTC. A pregnancy test was positive. 
The patient elected to terminate her pregnancy prior to undergoing total thyroidectomy. Histopathology of the removed gland confirmed multifocal, well-differentiated PTC affecting the entire gland with vascular invasion and metastases to multiple lymph nodes (Figures 3A and B). A withdrawal iodine-123 scan (TSH $90.6 \mathrm{mcIU} / \mathrm{mL}$ ) showed intense uptake in the thyroid bed, but none in the osseous lesions raising concern for a concurrent second primary malignancy possibly originating from the organs that had been in the field of her previous radiation. However, no pathology was found on imaging of lungs and breasts. Repeat imaging of the neck did not reveal any distinct area of residual (normal) thyroid tissue explaining the radioiodine uptake. The T7 lesion was biopsied and found to be consistent with metastatic PTC (Figures 3C and D). Immunostain of the bone tissue was positive for thyroid-transcription factor-1; stain for mucicarmin was negative.

Figure 2. MRI of the cervical and thoracic spine.

2A, arrow and circle highlighting the area of bone fragment retropulsion and spinal stenosis. $2 \mathrm{~B}$, transverse view with arrows pointing to the enlarged thyroid lobes.
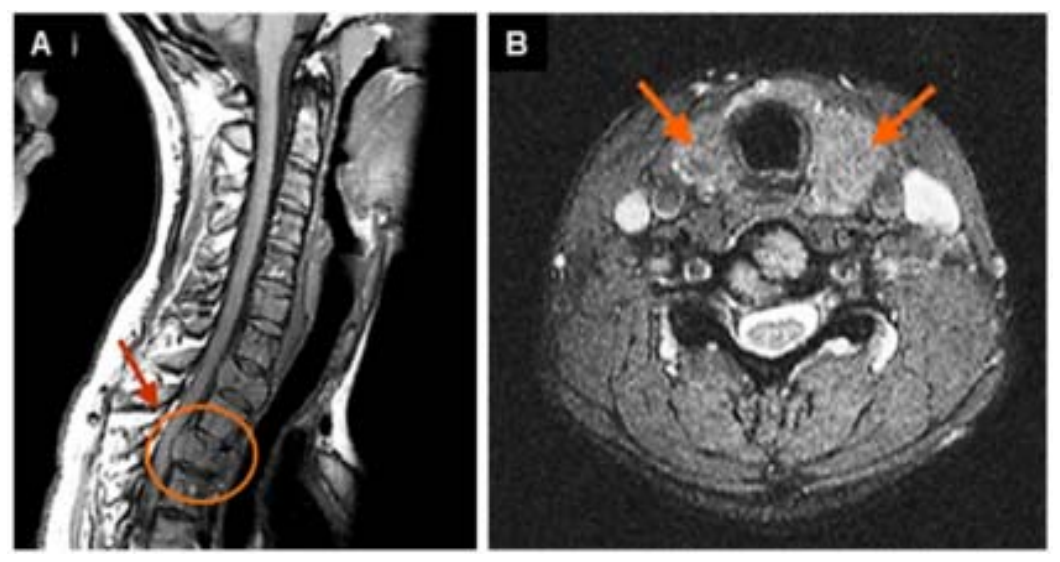

Figure 3. Light microscopy of the thyroid gland with PTC (A, B) and the biopsied T7 vertebral bone (C, D). Hematoxylin-eosin stain. $3 \mathrm{~A}$ and $\mathrm{C}$, original magnification $4 \mathrm{x}$. 3B, original magnification 40x. 3D,
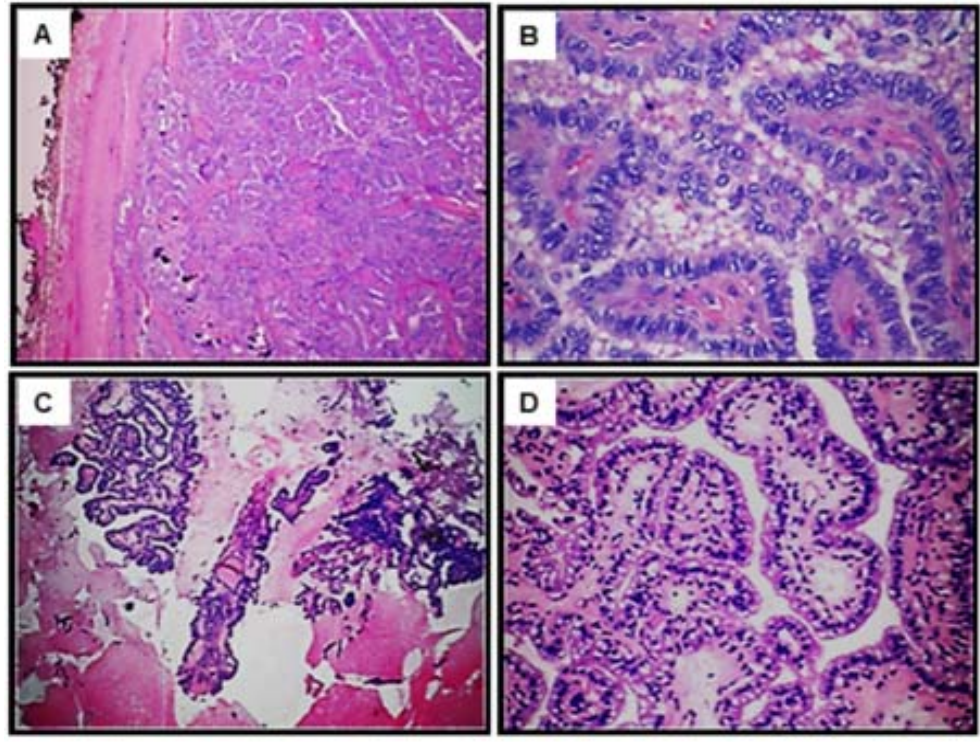
original magnification 20x.

The patient was placed on suppressive doses of levothyroxine (TSH $0.26 \mathrm{mcIU} / \mathrm{mL}$ ). The skeletal lesions were treated with palliative external beam radiation (2400 cGy). She received high-dose dexamethasone to alleviate the bone pain. The thyroid bed disease was ablated with $145 \mathrm{mCi}$ of iodine-131, given after intramuscular administration of thyrotropin alfa. Treatment with the tyrosine kinase inhibitor sorafenib was offered to her, but she declined. Three months later she developed progressively worsening muscle weakness and died of respiratory failure. 


\section{Discussion}

Most children and adolescents treated for Hodgkin's lymphoma survive long-term with the existing therapeutic interventions (chemotherapy and radiation), and are, therefore, at (7- to 18-times) higher risk for developing second malignant neoplasms (SMNs) compared with the general population ${ }^{[6]}$. While the risk of SMNs in adult Hodgkin's lymphoma survivors is smaller than for patients treated in childhood, and is, according to most studies, slightly higher for men than for women, the risk of pediatric survivors is higher for girls than for boys ${ }^{[7]}$. This had been attributed primarily to the occurrence of breast cancer in female individuals ${ }^{[6]}$, but was observed even after excluding breast cancer from risk analysis ${ }^{[8]}$.

The majority of SMNs ( $>75 \%$ ) occur within the previous radiation field; a smaller percentage develops outside of it or at a margin within $2 \mathrm{~cm}^{[8]}$. The time interval to the development of SMNs varies, but the median for solid tumors is approximately 10-15 years after diagnosis of Hodgkin’s lymphoma ${ }^{[8]}$.

The presence of radioiodine uptake in the thyroid bed and its concomitant absence in distant bony metastases of PTC, as observed in our patient, may illustrate the observation that low dose radiation (15 Gy -25.5 Gy) could have an even greater carcinogenic potential than previously thought, especially in girls ${ }^{[9]}$. The most common types of SMNs that occur with similar frequency and latency as with high-dose radiation are sarcomas, breast and thyroid carcinomas ${ }^{[9]}$.

Since PTCs generally do not present at this advanced stage as seen in our patient, it is conceivable that the combination of previous radiation and recent hormonal/immunologic changes due to two pregnancies within a relatively short time period has caused the marked aggressiveness of our patient's PTC, in addition to a possible (unknown) predisposition for malignancies. The incidence of thyroid cancer de-differentiation is reported to be between $2 \%-5 \%$. The prognosis of de-differentiated thyroid cancer is extremely poor with a median survival of several months only. Thyroid cancer de-differentiation is characterized by the cancer cells' loss of thyroid-specific features, such as loss of sodium/iodine symporter expression resulting in loss of iodine uptake ${ }^{[10]}$, reduced ability to produce thyroglobulin (this was however not the case in our patient), as well as loss of TSH receptors causing cellular unresponsiveness to the growth-regulating effects of TSH ${ }^{[11]}$. Although many cases of advanced PTC demonstrate de-differentiation and loss of radioactive iodine avidity, simultaneous occurrence of iodine-avidity and -resistance of PTC, as seen in our patient, is rarely observed.

In conclusion, a high degree of suspicion for SMNs is warranted in young female patients, who have undergone radiation treatment for Hodgkin's lymphoma in their childhood.

\section{Acknowledgements}

We thank Dr. Joseph Wiley for patient referral, Mr. Wesley Dixon for assistance with the radiographic images, Dr. Deepa Dutta for assistance with the histology images, and Dr. Marina Pratt for discussions about thyroid disease and pregnancy.

\section{References}

[1] Aschebrook-Kilfoy B, Ward MH, Sabra MM, et al. Thyroid cancer incidence patterns in the United States by histologic type, 1992-2006. Thyroid. 2011; 21: 125-134. PMid:21186939 http://dx.doi.org/10.1089/thy.2010.0021

[2] SEER Cancer Statistics Review, NCI Surveillance, Epidemiology, and End Results; 1975-2005.

[3] Smith LH, Danielson B, Allen ME, et al. Cancer related with obstetric delivery: Results of linkage with the California cancer registry. Am J Obstet Gynecol. 2003; 189: 1128-1135. http://dx.doi.org/10.1067/S0002-9378(03)00537-4

[4] De Groot L, Abalovich M, Alexander EK, et al. Clinical Practice Guideline: Management of Thyroid Dysfunction during Pregnancy and Postpartum: An Endocrine Society Clinical Practice Guideline. J Clin Endocrinol Metab. 2012; 97: 2543-2565. PMid:22869843 http://dx.doi.org/10.1210/jc.2011-2803

[5] Vasconcelos Alves G, Santin AP, 2 and Weber Furlanetto T. Prognosis of Thyroid Cancer Related to Pregnancy: A Systematic Review. J Thyroid Res. 2011; 2011: 1-5. PMid:21811666 http://dx.doi.org/10.4061/2011/691719 
[6] Bhatia S, Yasui Y, Robison L, et al. High risk of subsequent neoplasms continues with extended follow-up of childhood Hodgkin's disease: Report from the Late Effects Study Group. J Clin Oncol. 2003; 21: 4386-4394. PMid:14645429 http://dx.doi.org/10.1200/JCO.2003.11.059

[7] Armstrong G, Sklar C, Hudson M, et al. Long-term health status among survivors of childhood cancer: Does gender matter? J Clin Oncol. 2007; 25: 4477-4489. PMid:17906209 http://dx.doi.org/10.1200/JCO.2007.11.2003

[8] Constine LS, Tarbell N, Hudson MM, et al. Subsequent malignancies in children treated for Hodgkin's disease: associations with gender and radiation dose. Int J Radiat Oncol Biol Phys. 2008; 72: 24-33. PMid:18722263 http://dx.doi.org/10.1016/j.ijrobp.2008.04.067

[9] O’Brien MM, Donaldson SS, Balise RR, et al. Second malignant neoplasms in survivors of pediatric Hodgkin's lymphoma treated with low-dose radiation and chemotherapy. J Clin Oncol. 2010; 28: 1232-1239. PMid:20124178 http://dx.doi.org/10.1200/JCO.2009.24.8062

[10] Filetti S, Bidart JM, Arturi F et al. Sodium/iodide symporter: a key transport system in thyroid cancer cell metabolism. Eur J Endocrinol. 1999; 141: 443-57. PMid:10576759 http://dx.doi.org/10.1530/eje.0.1410443

[11] Brabant G, Maenhaut C, Kohrle J et al. Human thyrotropin receptor gene expression: expression in thryoid tumors and correlation to markers of thyroid differentiation and dedifferentiation. Mol Cell Endocrinol. 1991; 82: R7-12.

http://dx.doi.org/10.1016/0303-7207(91)90018-N 